\title{
CDISC SDTM Vaccination Evidence Source Terminology
}

National Cancer Institute

\section{Source}

National Cancer Institute. CDISC SDTM Vaccination Evidence Source Terminology. NCI

Thesaurus. Code C102590.

Terminology associated with the vaccination evidence source codelist of the Clinical Data Interchange Standards Consortium (CDISC) Study Data T abulation Model (SDT M). 